\title{
XVII. An account of the method of vanishing groups
}

\section{James Cockle Esq. M.A.}

To cite this article: James Cockle Esq. M.A. (1848) XVII. An account of the method of vanishing groups, Philosophical Magazine Series 3, 32:213, 114-119, DOI: 10.1080/14786444808645938

To link to this article: http://dx.doi.org/10.1080/14786444808645938

曲 Published online: 30 Apr 2009.

Submit your article to this journal \lceil

Џll Article views: 2

Q View related articles $\sqsubset$ 


\section{Mr. Cockle on the Method of Vanishing Groups.}

far too striking to be merely accidental. Moreover, it must not be forgotten that the observed numbers, as determined by Fraunhofer, are wholly independent of any hypothesis.

If the relation of whole numbers was rigorously true, the numbers in the foregoing table would stand as follows : 119 , 238, 476, 714, 833, 107 J, 1190.

The wave-length of the most luminous portion of the spectrum, the centre of the yellow space, is 2060 parts. If we take this as an optical centre, it will be found that the great lines are situated symmetrically in relation to it. $\mathrm{E}$ and $\mathbf{D}$ are equidistant above and below it; the same observation applies to $G$ and $B$, and also to $H$ and $A$. The only departure from this symmetry is in the case of $F$, which is not symmetrical with $\dot{C}$. It will be understood that I am here speaking of one of those spectra which are formed when a grating or ruled surface is used. In this the colours are arranged side by side, according to their wave-lengths; the centre of the spectrum, which is its most luminous portion, is occupied by the centre of the yellow space, and the light terminates at equal distances in the violet and red.

Do not these observations lead us to conclude, that the cause, whatever it may be, that produces these fixed lines is periodic in its action?

What that cause in reality is, we have not now facts sufficient to determine. I would not affirm that the disengagement of incombustible matter by a flame will always give rise to dark lines. But this is very clear; that in all those cases, as cyanogen, alcoholic solutions of nitrate of strontian, of boracic acid, \&c., in which these lines are developed, incombustible matter is uniformly disengaged.

University, New York, Dec. $25,1847$.

X VII. An Account of the Method of Vanishing Groups. By James Cockle, Esq., M.A., of Trinity College, Cambridge; Barrister-at-Law, of the Middle Temple*.

$\mathrm{N}$ a paper On certain Algebraic Functions just published in the Cambridge and Dublip Mathematical Journal, I have given a more detailed and connected view than I had previously done of the analysis which $\mathrm{I}$ have, since writing that paper, proposed toterm the Method of Vanishing Groups. I have employed this analysis, perhaps not altogether without success, in the theory of equations and in analytical geometry; and I indulge a hope that the following little account of the

* Communicated by Dr. Nathaniel Lister, latte Physician to St. Thomas's Hospital, \&c. 
manner in which, to the best of my recollection, the method occurred to my mind, may, as well as the subsequent portion of this article, prove to be not entirely uninteresting to some of the readers of the present Journal.

I was engaged upon the subject of the transformation of the general equation of the fifth degree into another of the same degree, in which the second, third, and fourth terms should be wanting. This transformation had already been effected by the peculiar processes of $\mathrm{Mr}$. Jerrard; but another method of arriving at it had occurred to me, suggested as follows.

In analytical geometry of two dimensions, when we desire to ascertain whether or not a given equation of the second degree between two variable quantities $x$ and $y$ represents a system of (in general) two straight lines, our object may be attained thus: multiply the given equation by four times the coefficient of $x^{2}$; add to and subtract from the equation, as it will now stand, the square of the coefficient of $x$ in the equation as it originally stood; the right-hand side of the equation being supposed zero, the left will then consist of the square of a linear function of $x$ and $y$, together with a quadratic function of $y$ only; now if four times the coefficient of $y^{2}$ in this quadratic function be multiplied into the part free from $y$, and this product be found to equal the square of the coefficient of $y$ in the quadratic function, that function is a square, and the given equation represents two straight lines, if the latter square be negative (or one only if the quadratic function disappears in the first instance, or a point if both the squares be positive).

This part of my studies at the University of Cambridge flashed across my mind in connexion with the problem respecting the equation of the fifth degree. The problem in question requires the solution of a linear, a quadratic, and a cubic equation; or rather, in the point of view from which I was considering it, of a quadratic and a cubic only. I now saw that there might exist a quadratic equation between two unknown quantities, which yet should involve us in no elevation af degree when one of those quantities was, by means of such quadratic, eliminated from another equation involving them. This favourable case of the quadratic occurs when that equation consists, or may be reduced to the form, of one or two squares, which, or one of which at least, involve both the unknown quantities.

Now whenever the qualratic function of $y$ vanishes, or is a perfect square, the given quadratic is of one of the forms just alluded to. In the latter case, which alone attracted my attention, the last-mentioned equation may be exhibited as the 
sum or difference of two squares, one of which will involve two, and the other one, of the undetermined quantities. And this sum or difference may be decomposed into linear factors, by equating one of which to zero we might eliminate $x$ or $y$ from any other given equation involving those quantities. No elevation of degree would ensue from such elimination. I reflected on this in considering the quadratic, which presented itself in the question of the before-mentioned transformation of the equation of the fifth degree.

But-how to impress this form on that quadratic? to render the quadratic function of $y$ a square? And here Mr. Jerrard's indeterminate method afforded me a useful suggestion-the answer was obvious. If we can render the system of given equations indeterminate, and so introduce an undetermined quantity into the coefficient of $y$ and into the term free from $y$ in the quadratic function of that quantity which remains after we have obtained a square by adding to and subtracting from the given quadratic (multiplied by four times the coeffcient of $x$ ) the square of the original coefficient of $x$-then by the aid of this undetermined quantity, can we not reduce the given quadratic to the required form, and so avoid elevation of degree in eliminating $x$ or $y$ between it and any other given equation? On trying this method I found it succeed. The result, which bears traces of the manner in which I obtained it, will be found at page 114 (art. 3) of the first volume of the Mathematician, although the notation used in this paper is different from that employed there. I have however here given the notation in which the idea is most likely to have suggested itself to my mind, and in which, if my memory serves me aright, it actually suggested itself.

Had I to discuss the same problem again, I should probably employ a homogeneous function of tour undetermined quantities, and, by successive operations of the same kind as those which I have indicated at page 267 of the current number of the Cambridge and Dublin Mathematical Journal, reduce it to a sum of four squares, and then make the sum of the first and second equal zero, as also that of the third and fourth. The fundamental principle of the whole method, according to the view which I now take of it, is, for homogeneous functions of the second degree, this reduction by a uniform process to squares as many in number as the undetermined quantities.

Investigations of very different classes may yet present features of resemblance in their results, their principles, or their processes. And wherever such resemblance exists, - be it in result, principle or process,-it can never, in a philosophic 
point of view, be valueless to indicate its traces. Regarded in this light, it is the solution of a quadratic by the ordinary process of completing the square that affords a first glimpse of the general process of the reduction of a general quadratic function of any number of variables to the form of a sum of squares. For, disregarding, as for this purpose we should do throughout, the signs of the squares, and considering as an algebraic square every numerical quantity, the usual solution of a quadratic is effected by reducing a certain quadratic function to the form of a sum of two algebraic squares.

Starting then from the solution of the quadratic as its cradle, we next see the same process occurring in analytical geometry of two dimensions, and availing us in inquiring into the conditions requisite in order that a given function of the second degree, and of two variable quantities, may be susceptible of reduction to the form of a sum of two algebraic squares (in which case the function represents a straight line or lines, or a point). In the present instance, by continuing the process with which we commence, we might reduce the given function to the form of a sum of three algebraic squares, the "algebraic square "last arrived at being obtained by subtracting the square of half the coefficient of $y$ in the quadratic function of that quantity alluded to in the third paragraph of this paper, from that part of the function which is free from $y$. As I have already stated, it was by combining a suggestion derived from the process of ascertaining the reducibility of a quadratic function of two variables to the sun of two squares, with an idea suggested by a contemplation of the indeterminate methods of Mr. Jerrard, that 1 devised the method of vanishing groups; and I take this opportunity of mentioning, with befitting sentiments, that it was my friend Dr. Nathaniel Lister of St. Thomas's Hospital, who, some ten years since, first directed my attention to Mr. Jerrard's Mathematical Researches, and induced me to undertake their perusal,--a pursuit to which I applied myself ardently during my second term's residence at Cambridge. 'The necessity, however, or at least the propriety, of devoting myself to other sciences and branches of science, prevented me from giving my exclusive attention to the theory of equations, ever a favourite study with me; but in the spring of 1844 I arrived at the method which forms the subject of this article, and it was published in the Mathematician for July of that year. It is different from a process which $I$ gave in a preceding volume (xxvi.) of this Journal, and to which I have elsewhere(Mechanics' Magazine, vol. xlvi.) given the name of the "method of symmetric products;" but I have employed it in this Magazine (see vols. xxvii. et seq.). 


\section{Mr. Cockle on the Method of Vanishing Groups.}

It was the opinion of an illustrious analyst, now no more, that the actual solution of the quadratic equation in general algebraical symbols contributed, in a greater degree than the solution of the cubic and of the biquadratic, to the advancement of algebra as a science (Murphy, Theory of Equations, page 1). And we may regard such solution under an aspect which did not meet the view of that great writer, -we may regard it as containing the germ of a process which enables us to exhibit far more general functions than those involved in the quadratic in the form of sums of powers, and which, combined with the indeterminate method when occasion requires, is capable of most extensive application in analysis. But it must never be forgotten that it was in the solution of a cubic that this indeterminate method - this great device of making a determinate problem algebraically indeterminate, and so solving it-was probably first elicited: and this circumstance ought to influence us materially in estimating the rank which the first discoverer of the solution of cubic equations is entitled to hold in scientific history. I consider the method of vanishing groups, when applied to the theory of equations, as the combination (accompanied by full developments) of the principle involved in the solution of the cubic with the process employed in that of the quadratic. Suggested, as it were, by a question in analytical geometry of two dimensions, that method admits of application in the analytical geometry of three dimensions; and $I$ have in fact so applied it in my Chapters on Analytical Geometry, now in course of publication in the Mechanics' Magazine. Its processes would evidently be capable of a similar extension to an analytical geometry of $n$ dimensions, had we any knowledge of an entity possessed of more than three dimensions. Were such things within the bounds of our faculties, there would be functions of their dimensions, linear ones for instance, which would bear an analogy to the corresponding ones of the three-dimensioned entity space (and the onedimensioned entity time), and which would by this method be discussed in a manner similar, or at all events but slightly different from, that of space (or time).

In conclusion, I may mention a point in which our results so closely resemble those deduced in another department of science, as to have suggested to me the name "Diophantic" as one which would be appropriate to our processes. I mean, that as in the Diophantine algebra we seek to form an equation, of which, if one side be zero the other shall consist of powers (squares, cubes, \&c.) of numerical quantities connecterl by the signs plus and minus, so in our analysis the object is in general to obtain an equation, of which, one side being zero, the other shall consist of powers of algebraical quantities 
(numerical or not) similarly connected. I say in general, because perhaps the preferable view of the problem, which is the object of our method, is to consider it as that of reducing certain algebraic functions, whether they be supposed equal to zero or not, to the form of a sum of algebraic powers.

Should it be thought that in the present article I have dwelt at unnecessary length on certain points, I should urge by way of apology, that before it can be fairly estimated all knowledge must be systematized. And I would add, that all knowledge is probably capable of being so dealt with, to an extent of which we can as yet form no idea.

2 Church-yard Court, Temple, November 8,1847 .

XVIII. Observations on the Geological Age of Bone-Caverns. By Richard Payne Cotron, M.D., Member of the Royal College of Physicians, London*.

THE geological period during which the caves of England formed the residences of wild beasts and cemeteries for the bones of their victims as well as themselves, is a subject of great interest, and can be best, if not exclusively ascertained, by comparing their animal remains with those of sedimentary deposits.

If a cabinet collection of cave specimens be contrasted with one of the Pleistocene freshwater formations, so great will appear the excess in the former, of small animals allied to, or identical with, those of our own times, that a date even more modern than "Pleistocene" might reasonably be given them. With a view of making a more just comparison, the following table has been constructed, showing the living and extinct animals common to both, and peculiar to each.

\begin{tabular}{|c|c|c|c|c|c|}
\hline \multicolumn{2}{|c|}{$\begin{array}{l}\text { Peculiar to sedimentary } \\
\text { deposits. }\end{array}$} & \multicolumn{2}{|c|}{ Pectuliar to caverns. } & \multicolumn{2}{|c|}{ Common to both. } \\
\hline Extinet. & Living. & Extinct. & Living. & Extinct. & Living. \\
\hline $\begin{array}{c}\text { Macacus } \\
\text { pliocenus. } \\
\text { Palæospalax } \\
\text { magnus. } \\
\text { Trogontherium } \\
\text { Cuvieri. } \\
\text { Rhinocer:s } \\
\text { leptorhinus. }\end{array}$ & Castor & $\begin{array}{l}\text { Ursus priscus. } \\
\text { Macharodus } \\
\text { latidens. } \\
\text { Lagomys } \\
\text { spelæeus } \\
\text { Fquus plicidens } \\
\text { Strongyloceros } \\
\text { spelæus. }\end{array}$ & $\begin{array}{l}\text { Vespertilio Noctula } \\
\text { klinolophus } \\
\text { ferrum-equinum. } \\
\text { Meles Taxus. } \\
\text { Putorius vulgaris. } \\
\text { Putorius erninius. } \\
\text { Canis Lupus. } \\
\text { Canis Vulpes. } \\
\text { Arvicolia agrestis. } \\
\text { Arvicola pratensis. } \\
\text { Mus musculus. } \\
\text { Lepus timidus. } \\
\text { Lepus Cuniculus. }\end{array}$ & $\begin{array}{l}\text { Ursus spelæus. } \\
\text { Hyæena spelæa. } \\
\text { Felis speliea. } \\
\text { Elephas } \\
\text { primigenius. } \\
\text { Rhinoceros } \\
\text { tichorhinus. } \\
\text { Equus fossilis. } \\
\text { Asinus fossilis. } \\
\text { Hippoputamus } \\
\text { mus scrofa. } \\
\text { Megaceros } \\
\text { Hibernicus. } \\
\text { Cervus Bucklandi. } \\
\text { Cervus Capreolus. } \\
\text { Bos primigenius. } \\
\text { Bos longifrons. }\end{array}$ & $\begin{array}{l}\text { Felis catus. } \\
\text { Arvicula } \\
\text { amphibia. } \\
\text { Cervus } \\
\text { Elaphus. } \\
\text { Cervus } \\
\text { Tarandus. } \\
\text { Capra Hireus. } \\
\text { Bison priscus } \\
\text { Aves (?) }\end{array}$ \\
\hline
\end{tabular}

